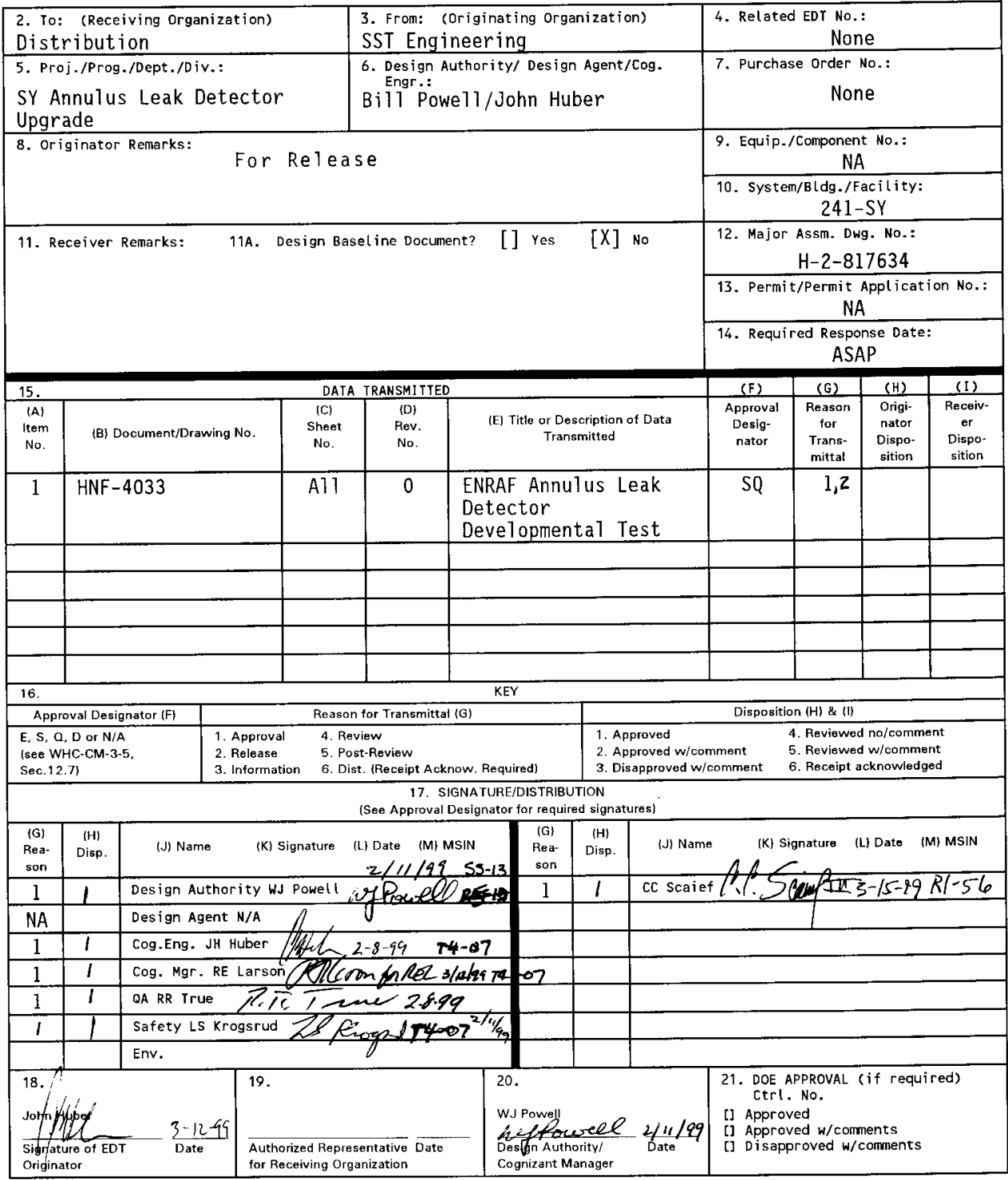




\title{
ENRAF Annulus Leak Detector Development Test
}

John Huber

Lockheed Mart in Hanford Corporation, Richland, WA 99352

U.S. Department of Energy Contract DE-AC06-96RLI3200

\author{
EDT/ECN: $616406 \quad$ UC: 512 and 2030 \\ Org Code: $74800 \quad$ Charge Code: 106773/BC20 \\ B\&R Code: EW312007l Total Pages: 8
}

Key Words: Enraf, Gauge, Gage, ATG, 854, Leve1, LIT, Leve1 Indicating Transmitter, Density Indicating Transmitter, Annulus Leak Detector

Abstract: Development testing is performed to determine feasibility of using ENRAF 854 gauges as annulus leak detectors.

TRADEMARK DISCLAIMER. Reference herein to any specific comercial product, process, or service by trade name, trademark, manufacturer, or otherwise, does not necessarily constitute or imply its endorsement, recommendation, or favoring by the United States Government or any agency thereof or its contractors or subcontractors.

Printed in the United States of America. To obtain copies of this document, contact: Document Control Services, P.O. BOX 950, Mailstop H6-08, Richland WA 99352, Phone (509) 372-2420; Fax (509) 376-4989.
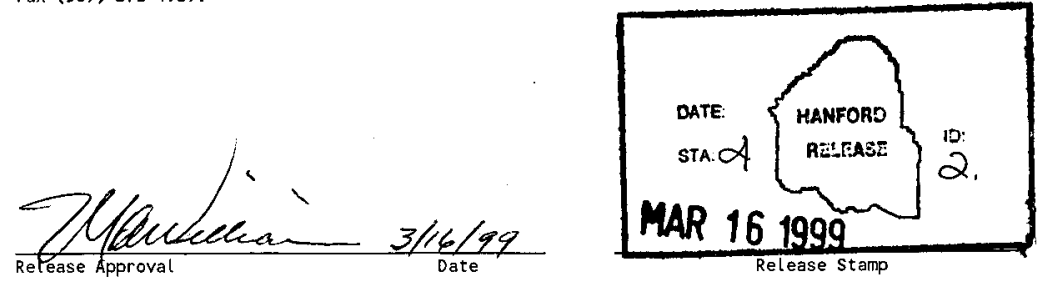

Approved for Public Release 


\section{RECORD OF REVISION}

(1) Document Number

HNF-4033

Page ]

(2) Title

ENRAF Annulus Leak Detector Development Test

CHANGE CONTROL RECORD

(3) Revision (4) Description of Change - Replace, Add, and Delete Pages

\begin{tabular}{l|ll}
0 & (7) & EDT 616406
\end{tabular}

0

Authorized for Release

(5) Cog. Angr. (6) Cog. Mgr. JH Huberlf/s-n RE Larson

(n)


Table of Contents

1.0 Purpose

2.0 Scope

3

3.0 Criteria

4.0 Description of Test

5.0 References

4

6.0 Test Procedure

5

Figure 1 


\subsection{Introduction / Purpose}

1.1 ENRAF 854 ATG level detectors are normally used for measuring and tracking waste levels in the Hanford waste tanks. Since instrument technicians and operators are familiar with these gauges, it has been suggested that ENRAF 854 's be used to alleviate problems with the existing annulus leak detector devices.

1.2 The purpose of this test is to determine the following.

1.2.1 The liquid level at which the gauge will report a change in leve!, given the displacer initially resting on the bottom of a container.

1.2.2 Whether the high alarm level can be set at 0.25 inch above the bottom of the container.

\subsection{Scope}

This test and its results will be applicable to ENRAF 854 ATG level detectors used as annulus leak detectors.

\subsection{Criteria}

This is primarily an engineering development test. However there are certain results which will determine the usability of an ENRAF level gauge with standard displacer as an annulus leak detector. If the criteria are not met, the gauge may not be usable as an annulus leak detector device. However, it may also mean that a displacer of different design may be the solution.

\subsection{Level Detection}

With the displacer resting on the bottom of a container, the gauge must defect and report an addition of 0.25 inch of liquid or less.

\subsection{Alarm Activation}

The gauge must have the capability of setting the high alarm point at 0.25 inch above the bottom of the container. This setting must not incapacitate the gauge unless a suitable work-around is available. A work-around's suitability is determined by the cognizant engineer. 


\subsection{Description of Test}

\subsection{Location}

The test will be performed at MO-281 in the engineering offices. The ENRAF gauge will be installed on a portable cart.

\subsection{Test Method}

The test cart will be arranged as shown in Figure 1. A graduated, glass beaker will be placed under a standard polyethylene displacer. The gauge will be configured such that its zero point is located at some point below the bottom of the beaker. The level reading at the bottom of the beaker will be recorded and used to determine the 0.25 alarm setpoint above the bottom. The high alarm setting (HA) will be set equal to the bottom of beaker reading. This is because the expected immersion depth of the displacer is approximately 0.25 inch. In lieu of the beaker, any clear container may be used if accompanied by a graduated scale for measuring liquid depth.

The gauge will be placed into service and the displacer will be sent to rest on the bottom of the beaker. Water will be slowly added to the beaker until the gauge shows a change in level reading and/or an alarm is reported in the gauge display. Both the level at which the reading changes and the level at which the alarm activates will be recorded.

This process will be repeated 3 or more times and averages computed.

\subsection{References}

Instruction Manual Series 854 ATG Level Gauge, Enraf Inc., Part No. 4416.220, Version 2.2 (See CV-31560, vendor information file).

\section{H-2-817634, "INSTM ENRAF NONIUS ASSY INSTALLATION \& RISER SCHED," Revision 4, Dated July 3, 1997}




\subsection{Test Procedure}

6.1 Setup gauge per Figure 1.

6.2 Place a piece of card board over the beaker/container opening.

6.3 Enter command UN to cause the displacer to come to rest on the cardboard.

6.4 Enter command W2=ENRAF2 (protection level 2)

6.5 Enter command $\mathrm{RL}=+00020.00$

6.6 Enter command AR

6.7 Wait for gauge to reinitialize, then enter command $\mathrm{EX}$.

6.8 Wait for gauge to reinitialize, then enter command CA.

6.9 When displacer is $2-3$ inches above cardboard, enter command FR

6.10 Remove the cardboard

6.11 Ensure beaker/container is dry

6.12 Enter command UN to lower the displacer

6.13 When displacer comes to rest on the bottom of the beaker/container and the gauge reports a valid level reading (no exclamation point in display), record the level

Beaker bottom level inches

6.14 Enter protection level 2.

6.15 Enter command $H A=+x x x x x . x x$, where $x x x x x . x x$ is equal to the beaker/container bottom level.

6.16 Enter command EX and wait for gauge to reinitialize.

6.17 Enter command $\mathrm{CA}$ to raise displacer above beaker/container, then enter command FR to stop the displacer.

6.18 Place the card board on the beaker and enter command UN.

6.19 RECORD VERIFICATION that the displacer reports a valid level reading on top of the cardboard.

Valid level reading? Yes No

Signature

Date

6.20 Enter command CA then remove the cardboard.

6.21 Enter command UN and allow the displacer to come to rest on the bottom of the beaker/container.

6.22 Wait until the gauge reports a valid level reading. 
6.23 Using a measuring cup and an engineering scale, slowly add water to the beaker/container until one of the following occurs:

a. The level reaches 0.25 inches above the bottom of the beaker OR

b. The gauge reports a change in level of more than 0.02 inch $O R$

c. Indication of an high alarm level has bee reached.

6.24 DESCRIBE and RECORD the results of the above step.

6.25 If any of the substeps of step 6.24 do not occur, continue slowly adding water until all have occurred.

6.26 DESCRIBE and RECORD the results of the above step. 


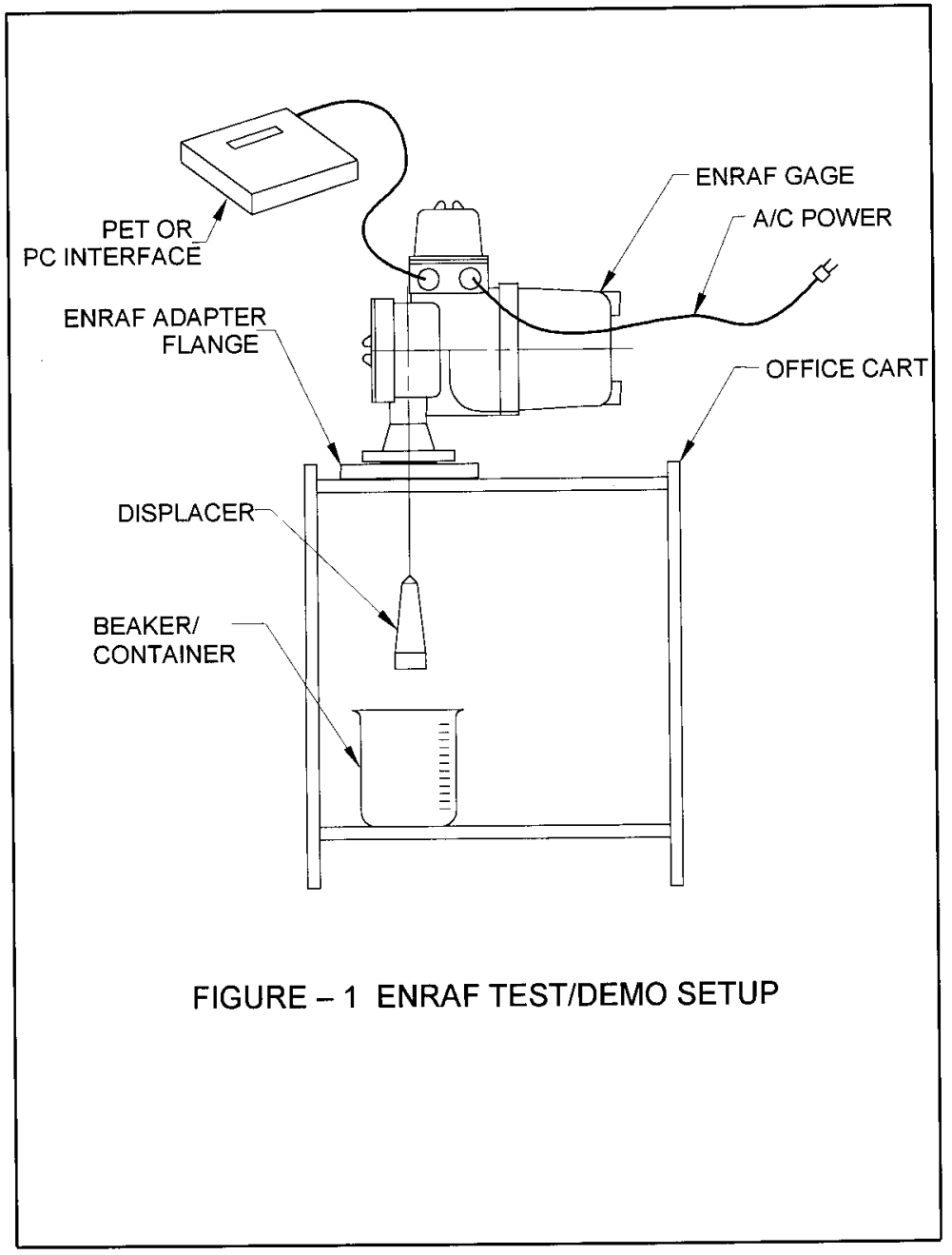

